\title{
Process Variables Optimization in Lapping of EN8 Material Using Taguchi Method
}

\author{
Rajesh Ramadass, Saravanan Sambasivam \\ Department of Production Engineering, PSG College of Technology, Coimbatore, India \\ Email address: \\ rajeshpsgtech2012@gmail.com (R. Ramadass), ssaramail@gmail.com (S. Sambasivam)
}

\section{To cite this article:}

Rajesh Ramadass, Saravanan Sambasivam. Process Variables Optimization in Lapping of EN8 Material Using Taguchi Method. Engineering Mathematics. Vol. 2, No. 1, 2018, pp. 50-55. doi: 10.11648/j.engmath.20180201.15

Received: May 30, 2018; Accepted: July 25, 2018; Published: September 12, 2018

\begin{abstract}
The main aim of this work is to minimize the surface roughness in the flat lapping of EN8 material. The process variables considered for the study were lapping time, abrasive size and abrasive carrier oil proportion. The mathematical model related to the lapping such as surface finish model, stress model and its significance was understood. The ( $\left.\mathrm{L}_{9}\right)$ orthogonal array in Taguchi method was utilized to conduct the experiments and surface roughness values were measured. The significance of each process variable on the surface roughness was studied using $\mathrm{S} / \mathrm{N}$ ratio results. From the results, it was inferred that most influence factor among process variables is abrasive carrier oil proposition in slurry. Response table showed a delta value of 0.1967 for the abrasive carrier oil proposition in slurry. The optimum combination of process variables was determined based on $\mathrm{S} / \mathrm{N}$ ratio and it was understood that minimum aluminum oxide abrasive proportion in slurry provides better surface quality in lapping of EN8 material. The optimum combination for minimum surface roughness were 15 minutes lapping time, $80 \mu \mathrm{m}$ abrasive size and 1:3 abrasive carrier oil proportion in slurry.
\end{abstract}

Keywords: Lapping, Surface Roughness, Taguchi Method, S/N Ratio

\section{Introduction}

In lapping process, chips were removed with loose grains distributed in lapping slurry which are guided through a shape transferring counterpart along undirected cutting paths. Good surface finish has become an essential part of product quality. One sided surface lapping process provides surface finish to a single surface of the component. Lapping differs from the other machining methods through the following characteristics. i) Most work pieces can be processed without being clamped or fixed. ii) Precision and ultra-precision machining can be executed in one operational step. iii) Changeover times are very short d) Components of less than $0.1 \mathrm{~mm}$ thickness can be machined iv) The minimal heating effect prevents undesired thermal distortions and structural changes in the work piece. v) A consistent machining quality is guaranteed for composite materials. vi) Lapped surfaces rarely exhibit tensile distortion or burr formation. vii) It is possible to machine multiple work pieces in one operational step. Jeoung-Du-Kim et al [1] determined the optimal combination of process variables for minimizing the surface roughness $\left(\mathrm{R}_{\mathrm{a}}\right)$ in the cylindrical fine ceramics $\left(\mathrm{Al}_{2} \mathrm{O}_{3}\right) \mathrm{S}$.
Chandrasekar and T. N. Farris [2] conducted experiments on ceramic materials by lapping and polishing with the abrasives suspended in between them in the form of slurry.

Brittle fracture was identified with lateral cracks intersecting the machined surface as the load applied by the abrasive particle was high. Kuo-Yi Chang et al [3]employed experimental design using Taguchi method to optimize the polishing parameterspressure, concentration and speed in lapping of gauge block. T. Shibata et al [4] found that the lapping performance except for the presence of occasional scratching should be solved by investigating particle characteristics and lapping procedures. J kang et al [5] studied the effect of lapping load in ceremic ball finishing of a novel eccentric lapping machine and identified that material removal rate increased linearly with the lapping load in the load range. B. D. Liu et al [6] conducted the experimental study on lapping and polishing of metal micro-coil based on silicon wafer which satisfies surface roughness requirements of the next layer in the micro mechanical electro magnetic relay. J. H. Lee, et. al [7] carried out some experiments with a machinable ceramic material $\mathrm{Si}_{3} \mathrm{~N}_{4}-\mathrm{BN}$ which is increasingly being employed in automobile bearings. The experiments showed the relationship of h-BN percentage of the lapping process, as the lapping time and wheel speed was 
changed Alit Suhas Deshpande et al [8] studied the effect of various abrasive materials in flat lapping and understood that surface finish improved with the hardness of the abrasive grit. Jiang Fan et al [9] used extention optimization theory for the optimization in lapping. The process parameters considered were lapping load pressure, the platen speed, the abrasive particle size, slurry flow and lapping fluid concentration to improve surface roughness and material removal rate. Sitthikorn Duangkaew [10] used steepest Ascent method based on factorial and simplex designs to improve surface roughness in surface lapping process. T. Dobrescu [11] et al studied the importance of brittle material processing in super finishing machine. Jian Bin Wang et al [12] proposed orthogonal experiment to study the effect of workbench speed, lapping pressure, the concentration of the triethonalamine, abrasive pad types on the material removal rate and surface roughness in the lapping of sapphire substrate with fixed diamond abrasive pad. Adam Barylski [13] et al conducted simulation and experiments to understand the influence of kinematic parameters on the flatness and quality of the work piece in single sided lapping process. A K Hussain et al [14] investigated the newly developed lapping tool on surface roughness. The theoretical and experimental values were compared the present study showed that newly developed lapping tool is capable to produce finer surface roughness. From the literatures it was understood that surface roughness characteristics in lapping process were influenced by the process parameters such as abrasive grit size, slurry concentration, time for lapping etc. The surface quality has a major impact on the perfomance of component in real time applications. The effect of process parameters in the lapping of EN8 material is yet to be studied, thus in this work an effort is made to optimize the process parameters influencing surface roughness in lapping process.

\subsection{Methodology}

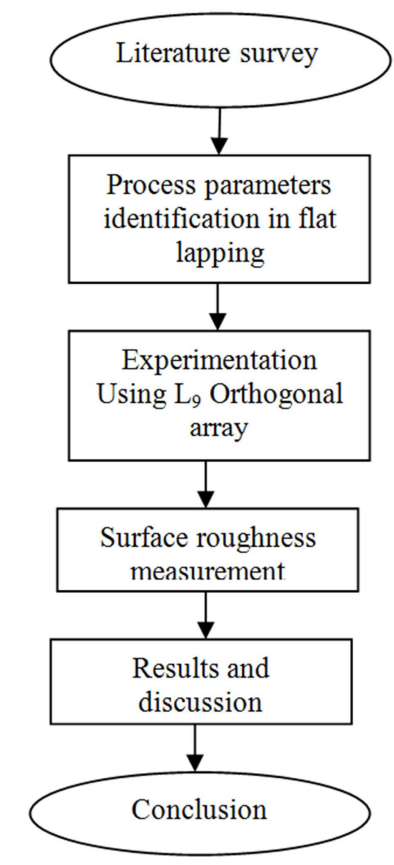

Figure 1. Methodology for Optimization in lapping.
The methodology planned to solve the problem in flat lapping of EN8 material is shown in the figure 1.

\subsection{EN8 Material Composition and Applications}

Chemical composition of the material is listed as follows

Carbon(c)-0.36

Manganese (Mn )-0.61

Phosphorus (P)-0.015

Sulphur (S)-0.005

Silicon (Si)-0.1

The applications of the material are found in

Crankshafts

Lightly stressed gears

Connecting rods

Automobile axle beams

\section{Surface Roughness and Surface Finish}

Surface roughness is a measurable characteristic based on the roughness deviations. The most commonly used measure of a surface texture is surface roughness shown in Figure 2. Surface finish is a more subjective term denoting smoothness and general quality of a surface. Surface roughness can be defined as the average of the vertical deviations from the nominal surface over a specified surface length. An arithmetic average (AA) method is generally used, based on the absolute values of the deviations, and this roughness value is referred to by the name average roughness. In equation form,

$$
R_{a}=\int_{0}^{l_{m}} \frac{[y]}{L_{m}} \mathrm{dx}
$$

Where $\mathrm{R}_{\mathrm{a}}=$ arithmetic mean value of roughness, $\mathrm{y}=$ the vertical deviation from nominal surface, $\mathrm{L}_{\mathrm{m}}=$ the specified deviation over which the surface deviations are measured. The equation1, perhaps easier to comprehend is given by

$$
R_{a}=\sum_{i=1}^{n} \frac{\left[y_{i}\right]}{n}
$$

Where $\mathrm{R}_{\mathrm{a}}=$ arithmetic mean value of roughness, $\mathrm{y}_{\mathrm{i}}=$ the vertical deviation converted to absolute value, $n=$ the number of deviations included in $\mathrm{L}_{\mathrm{m}}$.

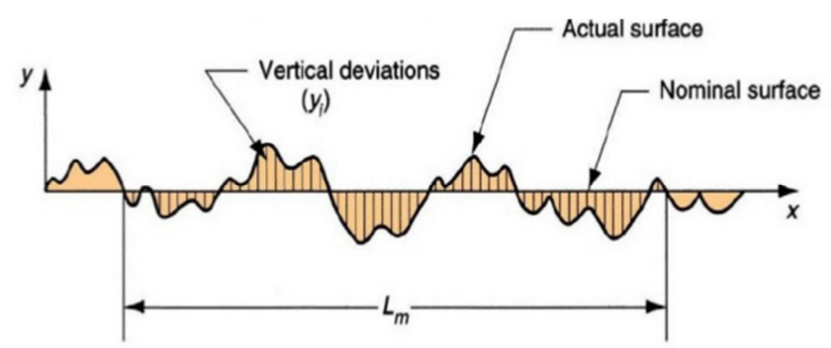

Figure 2. Deviations from the nominal surface [1].

Root Mean Square (RMS) technique is the alternative method used in surface roughness measurement. AA method is most widely used method throughout the universe for surface roughness measurement. Hence, in this work, AA 
method is used for surface roughness measurement.

\section{Mathematical Model}

Lapping is classified as finishing process that employs abrasive grains as cutting tools. For grinding models typical input process variables are feed rate, wheel and work speed, dress lead, ginding wheel diameter, type and size of abrasive grits. On the other hand output variables include metal removal rate, normal and tangential forces, surface integrity, wheel wear rate etc. Two models in grinding seems to be relevant to lapping process. The models are further explained.

\subsection{Surface Finish Model}

In this surface finish model, the root mean square $\left(\mathrm{R}_{\mathrm{g}}\right)$ value is extracted as a process variable and the depth of cut is selected as a design variable. A formula used to calculate the $\left(\mathrm{R}_{\mathrm{g}}\right)$ value of the surface after grinding, derived by Pandit and Sathyanarayanan [7] is shown in the Equation (3)

$$
\mathrm{R}_{\mathrm{g}}=\frac{A_{c}-7.596\left[\frac{F_{n}^{2} A g W_{g}^{2}}{b^{2} D}\left(K_{w}+K_{g}\right)^{2}\right]^{\frac{1}{3}}}{\sqrt{2}}
$$

$\mathrm{R}_{\mathrm{g}}$ : rms surface roughness value

$A_{C}$ : amplitude of the secondary wavelength of the wheel profile

$\mathrm{F}_{\mathrm{c}}$ : normal thrust force on the wheel

$\mathrm{A}_{\mathrm{g}}$ : amplitude of the primary wavelength of the wheel profile

$\mathrm{W}_{\mathrm{g}}$ : wavelength of the primary wavelength of the wheel profile

b: width of cut

D: diameter of the wheel

$\mathrm{K}_{\mathrm{W}}:\left(1-v_{w}^{2}\right) / \pi \mathrm{E}_{\mathrm{W}}$

$v_{\mathrm{w}}$ : poisson's ratio for workpiece, $\mathrm{E}_{\mathrm{W}}$ : elastic moduli for workpiece

$$
\mathrm{K}_{\mathrm{g}:}\left(1-v_{g}^{2}\right) / \pi \mathrm{E}_{\mathrm{g}}
$$

$v_{\mathrm{g}}$ : poisson's ratio for grit, $\mathrm{E}_{\mathrm{g}}$ : elastic moduli for grit

Surface finish is among potential parameters in both lapping and grinding. $\mathrm{R}_{\mathrm{g}}$ is non linearly related to most of the parameters. However most of the parameters are considered irrelevant for lapping due to different process characteristics, particularly in term of tool used.

\subsection{Stress Model}

The grain strength strongly depends on particle size. The grain size and the uniaxial tensile strength in the following stress model were chosen as the design and process variables respectively.

$$
\sigma_{\mathrm{e}=1001 \frac{\mathrm{P}}{\mathrm{a}^{2}}}
$$

$\sigma_{e}:$ the effective uniaxial strength $(\mathrm{KPa})$

$\mathrm{P}$ : the load at fracture $(\mathrm{N})$

\section{A: dimension of the abrasive grains ( $\mathrm{mm}$ )}

The above equation is simple and applicable to lapping process. The investigation of the microstructure of abrasive grit and its effect beyond the scope of proposed work.

\section{Specification of Lapping Machine}

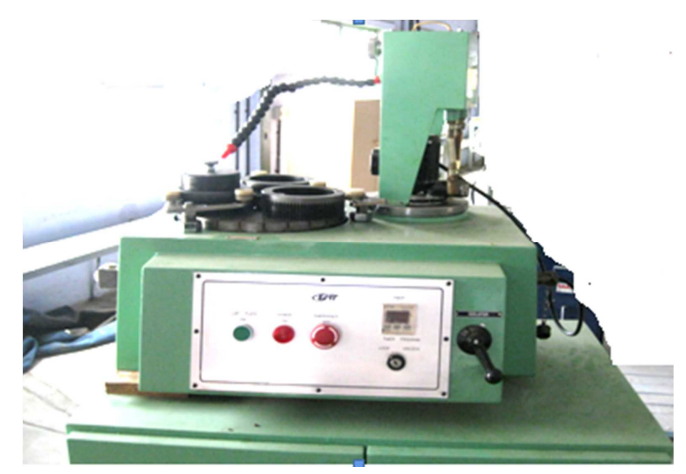

Figure 3. Lapping Machine.

Table 1. Specification of lapping machine.

\begin{tabular}{ll}
\hline Description & Value \\
\hline Lap plate OD & $300 \mathrm{~mm}$ \\
Conditioning ring ID & $107 \mathrm{~mm}$ \\
Length of machine $(\max )$ & $800 \mathrm{~mm}$ \\
Width of machine $(\max )$ & $675 \mathrm{~mm}$ \\
Height of machine $(\max )$ & $610 \mathrm{~mm}$ \\
Lap plate speed & $48 \mathrm{rpm}$ \\
Main motor & $0.37 \mathrm{~kW} / 0.5 \mathrm{hp}$ \\
Pump motor & $0.11 \mathrm{~kW} / 0.15 \mathrm{hp}$ \\
Timer range & $0-30 \mathrm{minutes}$ \\
No. of conditioning rings & 3 \\
Standard power supply & $415 \mathrm{~V} / 3 \mathrm{ph} / 50 \mathrm{~Hz}$ \\
\hline
\end{tabular}

\section{Sample Preparation and Test Procedure}

The work material used for the study was EN8 Steel, with a diameter of $30 \mathrm{~mm}$ and thickness of $20 \mathrm{~mm}$. The abrasives used were $\mathrm{Al}_{2} \mathrm{O}_{3}$ size 30,80 and 120 microns. The abrasives were mixed in 20W40 oil in the ratios of 1:1, 1:2, 1:3 (1 part of abrasive with 3 parts of carrier oil). The abrasive slurry was fed to the machine manually. The lapping machine employed the use of $5 \mathrm{~kg}$ unit load to supply the lapping pressure required. The machine was charged with the abrasive slurry for around 5 minutes before the experiment was started. This means that the lapping plate was operated without the work material with the abrasive slurry only. The machine was operated at a speed of 30 rpm. The lapping area was divided into 3 segments, each segment called a conditioning ring. A fixture was developed from cardboard to hold a maximum of 3 work pieces at a time in each conditioning ring. The lapping pressure applied to the work material during the course of lapping was $4.42 \mathrm{kPa}$. The slurry was stirred intermittently to prevent the abrasive particle from settling at the bottom of the container to ensure the uniform lapping of work material. The lapping machine was run for a time interval of 10 minutes, 15 minutes and 20 minutes respectively. The lapping machine controls such as timer, 
rotation speed and motor on/off were checked for proper functioning and trial specimens surface lapping was completed.

\section{Selection of Process Variables and Levels}

The operating conditions such as work material and the abrasive concentration which are generally controllable in any lapping situation were selected as factors for study. Three levels, having equal spacing, within the operating range of the machine were selected for each of the factors as shown in Table 2.

Table 2. Process variables levels.

\begin{tabular}{llll}
\hline Factor & Level 1 & Level 2 & Level 3 \\
\hline Abrasive Size $(\mu \mathrm{m})$ & $\mathrm{Al}_{2} \mathrm{O}_{3}$ & $\mathrm{Al}_{2} \mathrm{O}_{3}$ & $\mathrm{Al}_{2} \mathrm{O}_{3}$ \\
& 36 & 80 & 120 \\
Lapping Time(min) & 10 & 15 & 20 \\
Abrasive carrier oil proposition & $1: 1$ & $1: 2$ & $1: 3$ \\
\hline
\end{tabular}

\section{Taguchi Method and Optimization}

The Taguchi method is an experimental design technique that reduces the number of experiments dramatically through the application of orthogonal arrays and also minimizes the effect of the factors that are out of control. The greatest advantage of the Taguchi method was identified as decrease in experimental time, to reduce the cost and to find out significant factors in a shorter time period.

Optimization is a mathematical technique for finding a maximum or minimum value of a function of several variables subject to a set of constraints. It consists of the following steps.

\subsection{Model Variables}

The performance metrics was identified as surface finish, noise variables were identified as vibration, temperature and control factors were abrasive size, lapping time and abrasive carrier oil proposition.

\subsection{Variable Targets and Boundaries}

The minimum surface finish to be achieved is fixed as less than 1 micron and the boundaries for the tested variables were fixed in three levels minimum, medium and maximum. The effect due to noise variables were assumed as minimum.

\subsection{Experimental Plan and Matrix}

The signal to noise $(\mathrm{S} / \mathrm{N})$ ratio, which indicates the effect of each process variable on surface roughness, is calculated using the smaller the better criteria. The equation for the calculation of $\mathrm{S} / \mathrm{N}$ ratio is given in equation (3)

$$
\left(\frac{S}{N}\right)=-10 \log \left(\frac{1}{n} \sum_{i=1}^{n} \mathrm{y}_{\mathrm{i}}^{2}\right)
$$

Where $\mathrm{n}$ is the number of tests in a trial, $\mathrm{y}_{\mathrm{i}}$ is the response at the ith repetition. In order to examine the significance of each factor on the surface roughness. The experimental table with three parameters and three levels using $\left(\mathrm{L}_{9}\right)$ orthogonal array is shown in table 3 .

Table 3. $\left(L_{9}\right)$ Orthogonal array.

\begin{tabular}{llll}
\hline $\begin{array}{l}\text { Test } \\
\text { No }\end{array}$ & Time (mins) & Abrasive Size $(\boldsymbol{\mu m})$ & $\begin{array}{l}\text { Abrasive carrier oil } \\
\text { proposition }\end{array}$ \\
\hline 1 & 10 & 36 & $1: 1$ \\
2 & 10 & 80 & $1: 2$ \\
3 & 10 & 120 & $1: 3$ \\
4 & 15 & 36 & $1: 2$ \\
5 & 15 & 80 & $1: 3$ \\
6 & 15 & 120 & $1: 1$ \\
7 & 20 & 36 & $1: 3$ \\
8 & 20 & 80 & $1: 1$ \\
9 & 20 & 120 & $1: 2$ \\
\hline
\end{tabular}

\subsection{Trails}

The experiments were conducted adhering to the design matrix proposed in the table 3 . The surface finish values are measured using Mitutoyo surface roughness tester and the trails were repeated two times to check the experimental error and it was found to be minimum as shown in table 4 .

Table 4. Surface roughness results.

\begin{tabular}{lllll}
\hline \multirow{2}{*}{ Test No } & $\left(\mathbf{R}_{\mathbf{a}}\right)$ & & \multirow{2}{*}{ Avg $\left(\mathbf{R}_{\mathbf{a}}\right)$} & $\begin{array}{l}\mathbf{S} / \mathbf{N} \\
\text { ratio }\end{array}$ \\
\cline { 2 - 3 } & Trial1 & Trail2 & 0.34 & 9.37 \\
1 & 0.36 & 0.32 & 0.37 & 8.63 \\
2 & 0.38 & 0.36 & 0.19 & 14.42 \\
3 & 0.21 & 0.17 & 0.42 & 7.53 \\
4 & 0.39 & 0.45 & 0.12 & 18.41 \\
5 & 0.10 & 0.14 & 0.29 & 10.75 \\
6 & 0.26 & 0.32 & 0.27 & 11.37 \\
7 & 0.31 & 0.23 & 0.26 & 11.70 \\
8 & 0.24 & 0.28 & 0.38 & 8.40 \\
9 & 0.34 & 0.42 & & \\
\hline
\end{tabular}

\subsection{Analysis}

The statistical tool Minitab 13 is used in analyzing the test results. Test 4, 9 and 2 presented lowest $\mathrm{S} / \mathrm{N}$ values. Test 5 and 3 presented highest $\mathrm{S} / \mathrm{N}$ values. The analysis of data using is critical for improving the surface finish obtained from the lapping process. The knowledge of mathematics and statistics is considered important for interpreting the data from Taguchi design of experiments. The $\mathrm{R}_{\mathrm{a}}$ values obtained in trail 1 and trail 2 were found to be in close agreement. The average $R_{a}$ values were calculated from the trails and it used for $\mathrm{S} / \mathrm{N}$ values generation. The process variables optimization is based on the smaller the better $\mathrm{S} / \mathrm{N}$ value. Each process variable has three levels of $\mathrm{S} / \mathrm{N}$ value. minimum, medium and maximum. Maximum $\mathrm{S} / \mathrm{N}$ value with smaller the better condition is utilized for selecting the optimal process combination flat lapping process. Taguchi method is applied to improve the quality characteristics of lapping process. Mean of $\mathrm{S} / \mathrm{N}$ plot provides a graphical plot to interpret the optimal combinations in lapping process. 


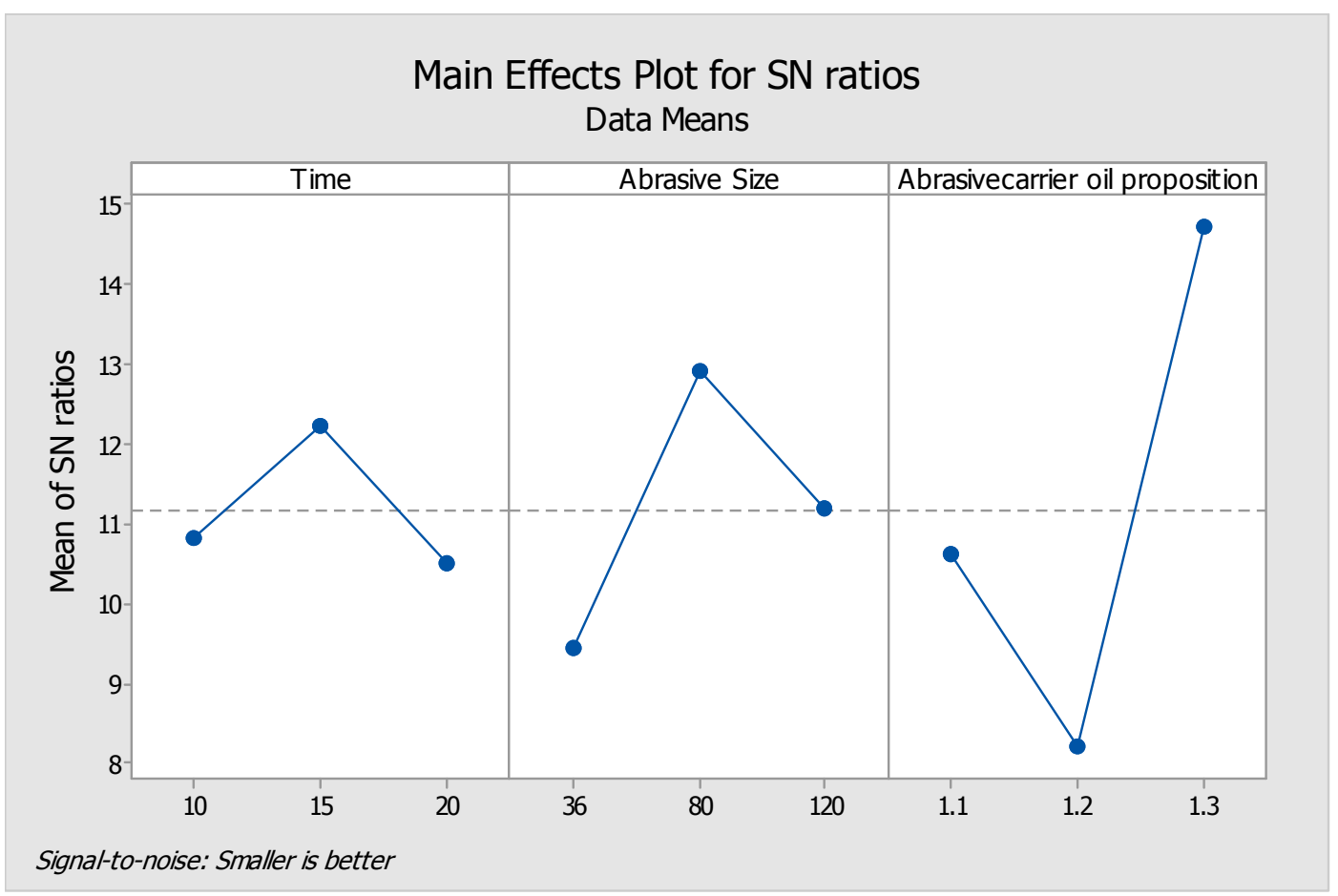

Figure 2. Mean effect plot for $S / N$ ratios.

From the Figure 2. Mean effect plot for $\mathrm{S} / \mathrm{N}$ ratios lapping time of 15 minutes, abrasive grade $80 \mu \mathrm{m}$ and abrasive carrier oil proposition ratio 1:3 were found to be the optimum combination of variables for minimizing surface finish in lapping process

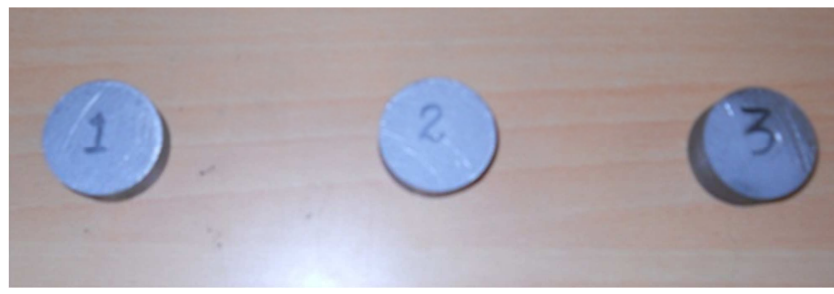

Figure 3. Results of trail 2-test no $1,2 \& 3$.

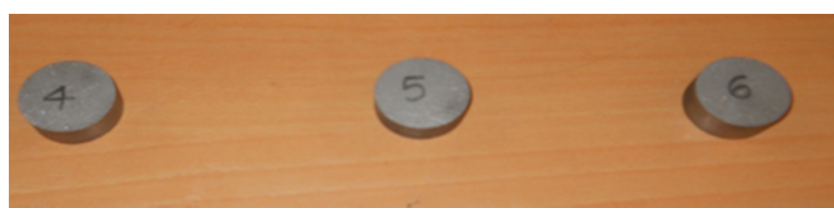

Figure 4. Results of trail 2-test no $4,5 \& 6$.

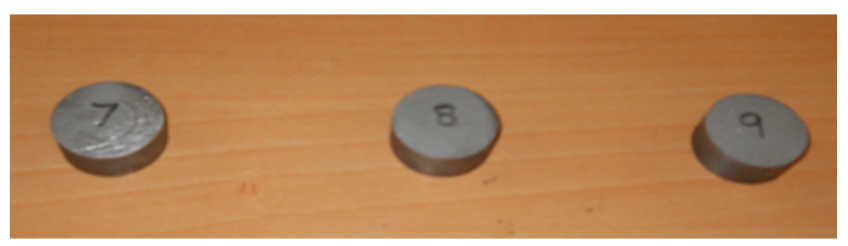

Figure 5. Results of trail 2-test no 7, $8 \& 9$.

The images of the surface finished parts in the lapping experiment are shown in the Figure 3, Figure 4 and Figure 5.

\begin{tabular}{|c|c|c|c|}
\hline & & brasive & Abrasivecarrier \\
\hline Level & Time & Size & oil proposition \\
\hline 1 & 0.3000 & 0.3433 & 0.2967 \\
\hline 2 & 0.2767 & 0.2500 & 0.3900 \\
\hline 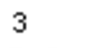 & 0.3033 & 0.2867 & 0.1933 \\
\hline elta & 0.0267 & 0.0933 & 0.1967 \\
\hline ank & 3 & 2 & \\
\hline
\end{tabular}

Figure 6. Response table for means.

From the Figure 6. Response table for means it was inferred that abrasive proportion in slurry as the most critical parameter affecting surface finish. Abrasive size and time was identified as secondary and tertiary parameter. The confirmation test was completed for the optimal combination of results obtained. The surface finish values were found to be minimum and value obtained from the test was 1.08 micron. The incontrollable noise factors like vibration, temperature effect on the surface finish is considered as minimum. Experiments performed in a controlled atmosphere with vibration damping systems will be considered in the future scope of this work.

\section{Conclusion}

The flat lapping of EN8 material with abrasive material, abrasive carrier oil proposition in slurry and time as input process variables was carried out and following conclusions were obtained.

i) The major factor influencing surface roughness in the rank-wise is abrasive carrier oil proportion in slurry, abrasive size and time.

ii) Optimum combination of process variables which minimizes surface roughness were identified as 15 minutes 
lapping time, $80 \mu \mathrm{m}$ abrasive size and 1:3 abrasive carrier oil proportion in slurry ( 1 part of abrasive with 3 parts of carrier oil) from the $\mathrm{S} / \mathrm{N}$ graph of Taguchi method.

\section{References}

[1] Jeoung-Du-Kim, Min-Seong Choi, "A study on the optimization of the cylindrical lapping process for engineering fine ceramics $\left(\mathrm{Al}_{2} \mathrm{O}_{3}\right)$ by the statistical design method", Journal of Material ProcessingTechnology(1995), pp368-385.

[2] Chandrasekar and T. N Farris, "Mechanics of Polishing", Journal of Applied Mechanics (1998). Vol 65(2) pp 410-416.

[3] Kuo-Yi Chang, Yu-Hua Song, Tsann-Rong Lin, "Analysis of lapping and polishing of a gauge block", International Journal of Advanced Manufacturing Technology (2002). Vol 20(6) pp 414-419.

[4] Shibata, B. Golman, k. Shinohara H. C, "Profile analysis of surfaces lapped with diamond particles of several shapes", Wear Journal (2003). Vol 254(8) pp 742-748.

[5] J kang, M Hadfield, "The effects of lapping load in finishing advanced ceramic balls on a novel eccentric lapping machine", Institution of Mechanical Engineers (2005). Vol 219 (7) pp 505-513.

[6] J H Liu, Z J Pei, Graham R. Fisher, "Grinding wheels for manufacturing of silicon wafers: A literature review", International Journal of Machine Tools and Manufacture (2007). Vol 47(1), pp1-13.

[7] J. K. Won, Y. J. Chun, M. W. Cho, J. H. Lee., "Ultra-precision lapping of machinable ceramic $\mathrm{Si}_{3} \mathrm{~N}_{4} \mathrm{BN}$ by in process electrolytic dressing", International Journal of Advanced Manufacturing (2007). Vol 31(12). pp 1101-1108.

[8] Lalit Suhas Deshpande, Raman, Sunanta, Agbaraji, "Observations in flat lapping of stainless steel and bronze", Wear Journal (2008). Vol 265, pp105-116.
[9] Fan Jiang, Jian Hua Xiang, Zhong Wei Liang, Chun Liang Zhang, "The Optimization of Lapping Process Parameters Based on Extension Theory", Key Engineering Materials, Vols. 531-532, pp. 262-265, 2012.

[10] Sitthikorn Duangkaew · Pongchanun Luangpaiboon, "Surface Lapping Process Improvement via Steepest Ascent Method Based on Factorial and Simplex Designs," (2013).

[11] Tiberiu Dobrescu, Nicoleta-Elisabeta Pascu, Gabriel Jigs, ConstantinOpran, "Optimization criteria of Plane Lapping Machines”, (2014) Procedia Engineering, Vol 100, pp428-434

[12] Jian Bin Wang, Zhen Li, Hong Gao, Da Shu, Ping Xiao, "Process Optimization of Lapping Sapphire Substrate with Fixed Diamond Abrasive Pad", Key Engineering Materials, (2016), Vol. 693, pp. 1090-1097.

[13] Adam Barylski "Optimization of kinematic parameters in single sided lapping”, doi: 10.17814/mechanik.2017.10.134

[14] A K Hussain, K Q Lee, L M Aung, A Abu1, L K Tan and H S Kang, "IOP Conference Series: Materials Science and Engineering, doi:10.1088/1757-899X/290/1/012014

[15] Lynah, P. R., "Lapping," ASM Handbook, Vol. 16, 1989, pp. 492-505.

[16] Subramanian, K., "Finishing Methods Using Multipoint or Random Cutting Edges," ASM Handbook, Vol. 5, 1994, pp. 90-91, 105-106.

[17] Indge, John H., "Lapping, Honing, and Polishing," ASM Handbook, Vol. 4, 1992, pp. 351-358.

[18] Brooman, Eric W., "Design for Surface Finishing," ASM Handbook, Vol. 20 (Material Selection and Design), pp. 820827.

[19] Paul Mathews, "Design of experiments with MINITAB," 2005, pp 93-105. 